\title{
A PROBLEMATIZAÇÃO DA ABORDAGEM TEMÁTICA NA FORMAÇÃO INICIAL DE PROFESSORES DE QUÍMICA
}

\author{
Renata Aragão da Silveiraa, ${ }^{\mathrm{a},\left(\text { Lya Piaia }^{\mathrm{a},(\mathbb{C}} \text { e Fábio Peres Gonçalves }\right.}{ }^{\mathrm{a}, *,(\mathbb{1}}$ \\ aDepartamento de Química, Universidade Federal de Santa Catarina, 88040-900 Florianópolis - SC, Brasil
}

Recebido em 06/05/2020; aceito em 30/06/2020; publicado na web em 21/08/2020

\begin{abstract}
THE PROBLEMATISATION OF THE THEMATIC APPROACH IN THE INITIAL TRAINING OF CHEMISTRY TEACHERS. The thematic approach supported by Paulo Freire's reference has been the object of study in the Teaching of Nature Sciences. In this work we analyzed which knowledge is explained by two undergraduate students about limits and potentialities related to the planning and development of a thematic approach promoted in the context of a supervised curricular internship of a degree course in Chemistry. The examination of the knowledge of the graduates registered in a collective virtual diary was guided by assumptions from the perspective of the teacher as researcher of the practice itself and the procedures of discursive textual analysis. The analysis highlights that part of the knowledge explained by the undergraduates refers to the choice of topic and content of Chemistry to be addressed and the organization of classroom activities, which sometimes move away from a progressive perspective of education. Finally, it is pointed out that certain knowledge explained by the students as a potentiality in the thematic approach may keep in itself a certain limit that needs to be problematized, reinforcing to some extent the importance of the theoretical-methodological approach that guided the formative process.
\end{abstract}

Keyword: chemistry teaching; thematic approach; Paulo Freire.

\section{INTRODUÇÃO}

As discussões sobre a relevância das aulas de Ciências da Natureza são pujantes na literatura. Stuckey et al., ${ }^{1}$ no entanto, chamam atenção para a diversidade de significados subjacentes à expressão "relevância" e mencionam a influência de ideias do renomado educador brasileiro Paulo Freire na disseminação de um significado que valoriza a realidade do educando como constituinte do seu processo formativo.

Delizoicov ${ }^{2}$ apresenta as contribuições, particularmente de pesquisadores brasileiros, na articulação de pressupostos da educação defendida por Paulo Freire com o Ensino de Ciências da Natureza direcionadas à educação básica. Essas contribuições se destacam por meio de publicações a partir da década de 1980. No Ensino de Química é notória a proposta pautada em um ensino de temas socialmente relevantes aos estudantes ${ }^{3,4}$ que ficou conhecida como temas sociais. E mais recentemente Halmenschlager e Delizoicov ${ }^{5}$ sistematizaram, a partir de um levantamento de referências na literatura, a abordagem de temas no Ensino de Ciências da Natureza, dentre as quais se encontra aquela fundamentada em ideias de Paulo Freire, especialmente no que o autor cunhou de tema gerador. Nessa abordagem, problemas do contexto discente são a gênese do processo educativo. ${ }^{6}$

Halmenschlager et al. ${ }^{7}$ ressaltam que a abordagem temática tem sido incorporada na educação básica com uma perspectiva distinta da que vem sendo incentivada na formação inicial de professores. Portanto, ainda que haja pujança na abordagem temática, incentivada por Freire, ${ }^{8}$ a sua presença na formação inicial de professores ainda precisa ser objeto de reflexão. ${ }^{9}$

Nesse sentido, considerando a importância de elucidar contribuições de processos de formação docente na incorporação da abordagem temática no ensino de Ciências da Natureza, temos como objetivo de pesquisa analisar quais conhecimentos foram explicitados por licenciandas sobre limites e potencialidades relativos ao planejamento e

*e-mail: fabio.pg@ufsc.br desenvolvimento de uma abordagem temática promovida no contexto de um estágio curricular supervisionado de um curso de Licenciatura em Química, de modo a identificar possíveis contribuições desse processo formativo. Ele foi orientado por uma proposta fundamentada na ideia de diálogo problematizador de Paulo Freire direcionada à formação de professores. ${ }^{10}$ Diferentemente do trabalho de Gonçalves, Biagini e Guaita, ${ }^{10}$ a proposta aqui considerada foi promovida em um contexto de estágio curricular.

\section{A ABORDAGEM TEMÁTICA E A FORMAÇÃO DE PROFESSORES DE CIÊNCIAS DA NATUREZA}

De acordo com Freire, ${ }^{8}$ a realidade do educando deve ser o ponto de partida para uma educação. Contempla-se nesse processo o diálogo, que deverá ser sobre conhecimentos - nos termos do autor - dos educandos e dos educadores. Portanto, o diálogo inicia no momento em que o educador busca apreender sobre o que será objeto de estudo. ${ }^{8}$ De acordo com Freire ${ }^{8}$ o diálogo não pode ocorrer em situação de dominação de um pelo outro: "a educação autêntica [...] não se faz de "A" para "B" ou de "A" sobre "B", mas de "A" com "B" mediatizados pelo mundo" (p. 98). ${ }^{8}$ Deste modo, é possível construir conhecimentos em conjunto, o que não significa que o diálogo não implique em tensões entre diferentes pontos de vista, pelo contrário. ${ }^{8}$ Espera-se que os educandos não sejam alienados por diferentes intenções, mas que conquistem a sua emancipação. ${ }^{8} \mathrm{Com}$ esse intuito, a educação contempla ação e reflexão.

Parte dos trabalhos da área de Ensino de Ciências da Natureza que dialogam com as contribuições de Paulo Freire faz menção ao que foi denominado pelo educador brasileiro de investigação temática. Essa investigação é constituída de cinco etapas, conforme sistematização de Delizoicov ${ }^{11}$ e que, de forma resumida, podem assim serem definidas:

1) levantamento preliminar: consiste na identificação de informações em fontes diversas relativas à localidade em que vivem os educandos;

2) análise das situações e escolha das codificações: a partir do exame das informações apreendidas na etapa anterior, selecionam-se 
situações significativas que remetam a contradições a serem exploradas futuramente no processo educativo;

3) diálogos descodificadores: constitui o processo em si de apreensão do tema gerador. Nele podem participar educandos e outros cidadãos da localidade em questão em que por meio de uma dinâmica dialógica problematizadora se confirmam de fato as situações significativas elencadas na etapa preliminar. $\mathrm{O}$ tema gerador, nas palavras de Paulo Freire, é orientado para o diálogo sobre as contradições sociais presentes na realidade do educando; ${ }^{12}$

4) redução temática: é a elaboração do programa com a seleção de conteúdos disciplinares imperativos à compreensão do tema gerador e o planejamento do processo educativo;

5) desenvolvimento em sala de aula: consiste na realização das atividades planejadas na etapa anterior, contemplando os conteúdos previamente selecionados.

Embora o processo de investigação temática tenha sido elaborado para o contexto da educação não formal, há décadas se estuda sua utilização na educação formal, ou seja, o ambiente escolar ${ }^{13}$ e na formação de docentes. ${ }^{9}$

Delizoicov, Angotti e Pernambuco ${ }^{14}$ sinalizam critérios para a seleção de determinados conteúdos da área de Ciências da Natureza na escola, considerando as ideias de Freire ${ }^{8}$ relativas ao processo de investigação temática. Essas contribuições, quando incorporadas no campo curricular no Ensino de Ciências da Natureza, são descritas como Abordagem Temática Freiriana. ${ }^{15}$

As etapas do processo de investigação temática não precisam ser seguidas rigidamente para favorecer uma abordagem temática na educação básica. ${ }^{16}$ Contudo, são interpretadas como um direcionamento para contemplar características importantes no processo educativo. A aprendizagem de determinados conhecimentos em detrimento de outros colabora para que os estudantes possam se envolver no processo de transformação da realidade em que vivem. Essa transformação, a partir dos conhecimentos construídos, constitui-se na humanização dos discentes. ${ }^{17}$

Halmenschlager e Delizoicov ${ }^{5}$ identificaram em trabalhos que se enquadram na abordagem temática apoiada nas ideias de Paulo Freire uma defesa de tal abordagem para a conscientização dos discentes acerca da sua realidade, de modo a caracterizar explicitamente uma perspectiva educacional de não neutralidade. ${ }^{5}$ Também a partir de um levantamento de referências na literatura, Hunsche, Silva e Hirata ${ }^{18}$ destacam temas que aparecem apenas como um meio para trabalhar um conceito científico na educação básica. Apesar de reconhecer que determinadas propostas de abordagem temática impliquem em tal perspectiva, compreendemos que ela, quando incorporada na abordagem temática incentivada por Freire, ${ }^{8}$ restringe a reflexão docente sobre conteúdos que possam auxiliar na compreensão da realidade em que docentes e discentes estão imersos, o que compromete os objetivos da educação defendida por Paulo Freire.

Portanto, ainda que a abordagem temática pautada em Freire ${ }^{8}$ seja compreendida como um desafio, ela merece ser incentivada por diferentes componentes curriculares constituintes dos processos de formação de professores, sem negligenciar as dificuldades e resistências que são comuns a processos inovadores. ${ }^{18} \mathrm{Em}$ sintonia com essa defesa, Demartini ${ }^{15}$ destaca que após a definição de um tema gerador, diferentes caminhos podem ser percorridos de forma que o ensino de Ciências da Natureza possa contribuir à compreensão das contradições socioculturais.

No âmbito propriamente da formação de professores, Bomfim e Gehlen ${ }^{19}$ e Alves e Silva ${ }^{20}$ pontuam compreensões limitadas de docentes sobre os problemas sociais de estudantes submetidos aos processos educativos. Já Halmenschlager, Stuani e Souza ${ }^{21}$ reforçam a necessidade de uma formação docente pautada em colaborações de
Paulo Freire, contemplando um movimento de ação-reflexão-ação da prática pedagógica, entendida como práxis.

Sousa et al. ${ }^{22}$ ressaltam como uma dificuldade aos professores o pouco tempo historicamente disponibilizado a eles para o planejamento em conjunto de uma abordagem temática de acordo com a fundamentação teórico-metodológica de Freire. ${ }^{8}$ É, de fato, um problema para que os professores possam discutir e ampliar seus conhecimentos acerca da realidade escolar. ${ }^{18}$ Segundo Hunsche, Silva e Hirata, ${ }^{18}$ a organização do currículo a partir dos problemas sociais pode contribuir para a conscientização dos docentes acerca da realidade visando à mudança social. Em outras palavras, também potencializa a humanização dos professores. Para isso, os momentos de trabalho em conjunto mostram-se imprescindíveis, assim como a disponibilização de tempos e espaços para que possam ser promovidos.

Sousa et al. ${ }^{23}$ discorrem sobre a elaboração e desenvolvimento de atividades didático-pedagógicas acerca do tema lixo por estagiários atuantes na componente curricular Física no ensino médio. Os estagiários estudaram sobre a abordagem temática a partir das contribuições de Freire, ${ }^{8}$ de modo a aprenderem, dentre outros aspectos, a respeito da seleção de temas. Por meio da "adaptação" de etapas do processo de investigação temática os estagiários apreenderam o tema lixo, ao qual estiveram relacionados 15 planos de aula elaborados por eles, dos quais 7 puderam ser contemplados durante o estágio supervisionado. Basicamente, foi realizada a etapa de levantamento preliminar para obter informações relativas a dado contexto e caracterizar o tema a ser abordado. Ademais, apoiou-se na etapa de redução temática para escolher os conteúdos a serem ensinados aos estudantes na escola na etapa de desenvolvimento em sala de aula. Os estagiários registraram em um diário aspectos relativos à experiência educativa vivenciada na escola, incluindo aqueles associados às emoções. Para os autores, o estágio contribuiu, por exemplo, para que os licenciandos em Física valorizassem as "situações reais" dos estudantes da escola.

Em outro trabalho, Centa e Muenchen, ${ }^{24}$ vincularam etapas da investigação temática proposta por Freire $^{8}$ aos três momentos pedagógicos. ${ }^{14}$ Os três momentos pedagógicos podem ser assim caracterizados:

Problematização inicial

Apresentam-se situações reais que os alunos conhecem e presenciam e que estão envolvidas nos temas [...]. A meta é problematizar o conhecimento que os alunos vão expondo, de modo geral, com base em poucas questões propostas relativas ao tema e às situações significativas, questões inicialmente discutidas num pequeno grupo, para, em seguida, serem exploradas as posições dos vários grupos com toda a classe, no grande grupo.

[...] O ponto culminante dessa problematização é fazer que o aluno sinta a necessidade da aquisição de outros conhecimentos que ainda não detém, ou seja, procura-se configurar a situação em discussão como um problema que precisa ser enfrentado.

Organização do conhecimento

Os conhecimentos selecionados como necessários para a compreensão dos temas e da problematização inicial são sistematicamente estudados neste momento, sob a orientação do professor. As mais variadas atividades são então empregadas $[\ldots]$

Aplicação do conhecimento

Destina-se, sobretudo, a abordar sistematicamente o conhecimento que vem sendo incorporado pelo aluno, para analisar e interpretar tanto as situações iniciais que determinaram seu estudo como outras situações que, embora não estejam dire- 
tamente ligadas ao motivo inicial, podem ser compreendidas pelo mesmo conhecimento. (p. 200-202) $)^{14}$

Para Centa e Muenchen ${ }^{24}$ as três primeiras etapas da investigação temática se articulam ao primeiro momento pedagógico (denominado de estudo da realidade no trabalho das autoras) e a redução temática e o desenvolvimento em sala de aula, simultaneamente, à organização do conhecimento e à aplicação do conhecimento. As autoras investigaram um processo formativo com professores da área de Ciências da Natureza no qual os três momentos pedagógicos foram estudados como estruturantes do currículo escolar.

Torres et al. ${ }^{25}$ também desenvolveram um processo formativo com professores de uma escola que utilizou como referência teórico-metodológica de tal processo os três momentos pedagógicos. ${ }^{14}$ O trabalho examinou articulações entre as etapas da investigação temática ${ }^{8}$ - explorada em tal processo formativo - e as etapas da análise textual discursiva. ${ }^{26}$ Tratou-se, portanto, da associação entre uma proposta de estruturação curricular e um procedimento analítico utilizado em pesquisas, sobretudo, das áreas de Educação e Educação em Ciências, visando se afastar da abordagem puramente conteudista que pouco contribui para que os estudantes possam vislumbrar e enfrentar os problemas da realidade.

Por fim, destacamos mais uma vez o trabalho de Sousa et al.,${ }^{22}$ que reforçam em sua pesquisa que as condições de trabalho de docentes se constituem em uma dificuldade vigorosa para a implantação de temas geradores na escola. Contudo, as autoras defendem a importância de processos formativos com professores da educação básica na interação com a universidade que têm como objeto de estudo a perspectiva de abordagem temática apoiada nas contribuições do educador Paulo Freire. ${ }^{8}$ Em alguma medida, esses processos formativos, colaboram para a reflexão docente a respeito da sua prática pedagógica e, por sua vez, podem impactar as ações com estudantes.

Em suma, compreende-se que as contribuições de Paulo Freire para o contexto da educação têm sido tomadas como objeto de estudo por diferentes pesquisadores, incluindo aqueles que se dedicam ao Ensino de Ciências da Natureza e à formação de professores. Assim, em harmonia com os interlocutores citados aqui, ressalta-se ainda a necessidade de uma formação de docentes no sentido de promover a sua humanização e a dos estudantes submetidos aos processos educativos, de modo geral.

\section{O CONTEXTO DO DESENVOLVIMENTO DA ABORDAGEM TEMÁTICA NO ESTÁGIO SUPERVISIONADO, O DIÁRIO VIRTUAL COLETIVO E A SUA ANÁLISE}

Este trabalho considera as atividades de estágio supervisionado desenvolvidas em uma componente curricular (72 horas/aula) de um curso de licenciatura em Química de uma universidade pública brasileira. Essa componente curricular integrava o último semestre do curso previsto para conclusão em 4 anos e apresentava os seguintes conteúdos programáticos: a) projeto de ensino na perspectiva de uma abordagem temática; b) elaboração de materiais didáticos para o Ensino de Química; c) a formação docente na interação com a escola; e d) articulação entre ensino, pesquisa e extensão associada à formação de professores de Química e ao Ensino de Química. Esses conteúdos foram selecionados com base em conhecimentos expostos na literatura - a exemplo daqueles citados na seção anterior - sobre formação de professores, de modo geral, e formação inicial de professores de Química/Ciências, em particular. Destaca-se que o estágio supervisionado, realizado em contexto escolar caracterizado, soma-se a outros três na estrutura curricular do curso de licenciatura em Química em questão.
As atividades na componente curricular foram divididas em dois momentos: a) período anterior à observação de aula e regência na escola, no qual foram realizadas diferentes atividades; e b) períodos de observação de aula e regência na escola, realizados em dupla. Acerca das atividades desenvolvidas no primeiro momento, destacam-se:

- leitura individual e discussão em grande grupo de texto adaptado de Pimenta e Lima ${ }^{27}$ sobre a relação entre teoria e prática na docência. O texto foi lido em sala de aula e discutido a partir de perguntas previamente encaminhadas pelo formador;

- apresentação de seminários, sendo que cada uma das licenciandas, participantes dessa pesquisa, apresentou dois seminários apoiando-se em uma referência para cada um (trabalhos de Giacomini e Muenchen; ${ }^{16}$ Auler et al. ${ }^{28}$ Delizoicov; ${ }^{29}$ Delizoicov, Angotti e Pernambuco ${ }^{14}$ ) disponibilizada pelo formador. Da referência de Delizoicov, Angotti e Pernambuco ${ }^{14}$ foi lido um trecho relativo à abordagem temática, sustentada em ideias de Paulo Freire. A leitura do aporte teórico constituiu atividade extra-aula para as estagiárias;

- elaboração dos planos de aula e de materiais didáticos constituintes de um projeto de ensino construído em uma componente curricular preliminar, de acordo com proposta de abordagem temática a ser promovida no estágio. A elaboração dos planos de aula e de materiais didáticos, bem como a própria revisão do projeto de abordagem temática previamente planejado, foi orientada pelas discussões e referências relativas aos seminários. O segundo momento foi apresentado e discutido em publicação preliminar $^{30}$ que se recomenda a leitura para se acessar os detalhes do desenvolvimento do estágio supervisionado. Em síntese, foram desenvolvidas pelas estagiárias 6 horas/aula, após a observação de 2 horas/aula. Assim, foi possível desenvolver na escola, por diferentes motivos, somente uma parte do projeto de ensino que totalizou um planejamento de 21 horas/aula. O processo de planejamento do projeto está em sintonia com Sousa et al. ${ }^{23}$ no qual ocorreu uma investigação do tema a ser desenvolvido durante o estágio por meio de uma etapa da investigação temática, qual seja, o levantamento preliminar. ${ }^{8}$

Resumidamente, destaca-se que se buscou identificar aspectos da comunidade na qual a escola se inseria, de modo a escolher o tema e, por conseguinte, os conteúdos disciplinares. O tema escolhido foi moradia e a situação significativa contemplada nas aulas foi o tratamento de esgoto.

Durante o período de planejamento e desenvolvimento do estágio foi elaborado um diário virtual coletivo escrito pelas estagiárias e pelo formador responsável pela componente curricular. Foram convidados e incentivados a participar da produção do diário virtual coletivo o professor de Química da escola (supervisor) e uma estudante estagiária de docência de pós-graduação da área de Ensino de Ciências. Apesar de terem participado ativamente de outras atividades da componente curricular, não colaboraram com a escrita do diário virtual coletivo. No diário se descrevia além das atividades realizadas na componente curricular, o que inclui o período de observação e regência na escola, reflexões sobre as dificuldades e aprendizagens relativas ao planejamento e realização do projeto. O diário estava disponível na plataforma MOODLE (Modular Object-Oriented Dynamic Learning Environment) que, resumidamente, constitui-se em um ambiente virtual para favorecer o processo educativo. As licenciandas escreviam de forma periódica e alternadamente no diário e a cada registro delas o formador igualmente interagia elaborando contribuições por escrito.

O formador teve como prática a interação constante com o conhecimento explicitado pelas estagiárias por meio da leitura e escrita do diário virtual coletivo. Considerou-se como conhecimentos das licenciandas aqueles que elas traziam de suas vivências, independentemente do processo formativo, bem como aqueles que refletem em determinada medida o que foi aprendido na componente curricular 
de estágio supervisionado em questão, ou em outras componentes curriculares constituintes de seu curso de licenciatura em Química. Assim, seguimos a mesma proposta teórico-metodológica explicitada no trabalho de Gonçalves, Biagini e Guaita ${ }^{10}$ com a valorização de instantes de explicitação dos conhecimentos das licenciandas e de momentos de apropriação de novos conhecimentos, sendo a problematização a mediadora de ambos os momentos.

Assumiu-se a problematização no sentido colocado por Freire: "O diálogo problematizador não depende do conteúdo que vai ser problematizado. Tudo pode ser problematizado" (p. 53). ${ }^{31} \mathrm{O}$ autor complementa:

No fundo, em seu processo, a problematização é a reflexão que alguém exerce sobre um conteúdo, fruto de um ato, ou sobre o próprio ato, para agir melhor, com os demais na realidade.

Não há problematização sem esta última (Daí que a própria discussão sobre o além deva ter, como ponto de partida, a discussão sobre o aqui, que, para o homem, é sempre um agora igualmente). (p. 82-83) ${ }^{31}$

Cumpre notar que a problematização permeou não somente o processo de leitura e escrita do diário virtual coletivo, mas a componente curricular de estágio supervisionado em sua totalidade.

O formador orientou as estagiárias em relação a como realizar uma análise preliminar do diário virtual coletivo que subsidiou a escrita de um trabalho de conclusão da componente curricular na forma de artigo que tinha como objetivo geral relatar o processo de planejamento, desenvolvimento e avaliação do projeto de abordagem temática no Ensino de Química relativo ao estágio supervisionado.

O diário virtual coletivo se caracterizou, portanto, como uma ferramenta formativa e também de pesquisa, uma vez que foi tomado como um instrumento de obtenção de informações qualitativas submetidas à análise após encerramento da componente curricular e originando o presente trabalho. Apesar de os diários poderem gerar informações desvinculadas da atuação do pesquisador, no presente trabalho se adotou a perspectiva da análise do diário produzido no contexto de atuação dos pesquisadores, como um modo de favorecer a revisão da prática profissional dos envolvidos. ${ }^{32}$ Apoia-se em Freire $^{33}$ para responder a qualquer crítica à participação direta dos pesquisados no processo de análise:

Para muitos de nós, a realidade concreta de uma certa área se reduz a conjunto de materiais ou de fatos cuja existência ou não, de nosso ponto de vista, importa constatar. Para mim, a realidade concreta é algo mais que fatos ou dados tomados mais ou menos em si mesmos. Ela é todos esses fatos e todos esses dados e mais a percepção que deles esteja tendo a população envolvida. Assim, a realidade concreta se dá a mim na relação dialética entre objetividade e subjetividade. [...] Dizer que a participação direta, a ingerência dos grupos [...] no processo de pesquisa altera a "pureza" dos resultados implica na defesa da redução daqueles grupos a puros objetos da ação pesquisadora de que, em consequência, os únicos sujeitos são os pesquisadores profissionais. Na perspectiva libertadora em que me situo pelo contrário, a pesquisa como ato de conhecimento, tem como sujeitos cognoscentes, de um lado, os pesquisadores profissionais, de outro, os grupos [...] e, como objeto a ser desvelado, a realidade concreta. (p. 35) ${ }^{33}$

Freire $^{34}$ se refere a um tipo de investigação que não obrigatoriamente se caracteriza como aquela do professor pesquisador da própria prática. Todavia, reconhece-se que os seus posicionamentos coadunam com aqueles que advogam em favor da pesquisa como um princípio formativo para os professores. Aliás, posteriormente Freire ${ }^{34}$ defende explicitamente que não há docência sem a pesquisa. Na área de Ensino de Ciências da Natureza/Química são notórios os trabalhos que valorizam, sob diferentes abordagens teórico-metodológicas, a perspectiva do professor pesquisador, a exemplo daqueles de Maldaner ${ }^{35}$ Galiazzi,${ }^{36}$ Rosa, ${ }^{37}$ Abell,${ }^{38}$ El-Hani e Greca ${ }^{39}$ e Almeida et al. ${ }^{40}$ Compartilha-se neste trabalho do posicionamento de Almeida et al. ${ }^{40}$ sobre a interação entre professores da escola e professores da universidade em pesquisas realizadas de forma colaborativa entre ambos, qual seja, tal interação precisa ser caracterizada pela busca de um conhecimento que seja inédito tanto para os professores da escola quanto para os da universidade.

Destaca-se que a opção de trabalhar com a abordagem temática aqui caracterizada foi uma escolha das estagiárias dentre aquelas possíveis com base no que foi estudado nas componentes curriculares relacionadas com a elaboração do projeto de ensino e no diálogo com o contexto escolar. Assim, não houve qualquer imposição por parte do formador às estagiárias e ao contexto escolar. $\mathrm{O}$ fato de haver somente duas licenciandas na componente curricular é algo não raro e notável no contexto brasileiro de formação inicial de professores de Química, quando se considera as fases finais dos cursos de graduação. O formador responsável pela componente curricular de estágio supervisionado e as duas licenciandas são os autores deste trabalho.

Por fim, destaca-se que a análise textual discursiva ${ }^{26}$ orientou o exame do diário virtual coletivo. Esta análise é composta de três etapas:

$1^{a}$ etapa (unitarização): nesta se procedeu com a fragmentação do texto do diário virtual coletivo em unidades de significados relacionadas com o objetivo da pesquisa. Nesse processo se entenderam por limites no planejamento e desenvolvimento da abordagem temática fragmentos que remetessem, explícita ou tacitamente, à dificuldade, ao esforço dos participantes e aos desafios;

$2^{\text {a }}$ etapa (categorização): as unidades de significados previamente extraídas do diário virtual coletivo foram agrupadas no que se denomina de categorias emergentes - apesar do nome, salienta-se que essas não são originadas no vácuo teórico remetendo a uma compreensão problemática de neutralidade do processo interpretativo. A opção por categorias emergentes justifica a ausência de uma seção de referencial a priori para definir previamente categorias. As categorias construídas foram a identificação do tema e conteúdos para o estágio supervisionado de Química no ensino médio e as atividades de organização do conhecimento nas aulas de Química;

$3^{\text {a }}$ etapa (comunicação): das categorias foram produzidos textos descritivos e interpretativos, apresentados na sequência do trabalho. $\mathrm{Na}$ análise dos trechos do diário virtual coletivo foram utilizadas letras do alfabeto (A e B) para designar as estagiárias.

\section{ANÁLISE DAS INFORMAÇÕES QUALITATIVAS}

\section{A identificação do tema e de conteúdos para o estágio supervisionado de Química no ensino médio}

No que diz respeito à definição do tema, as licenciandas expressaram interpretações que remeteram a limites na apreensão de informações associadas à realidade investigada que se constitui como uma etapa essencial para a escolha do tema. Por exemplo:

Entretanto, percebeu-se que esse último recurso [questionário] utilizado, muitas vezes pode omitir certas situações devido a uma série de motivos. (B) 
No decorrer do planejamento a licencianda contraria sua expectativa tácita de que as respostas discentes ao questionário apontariam, com relativa segurança, informações que se buscavam sobre a realidade discente. Todavia é preciso compartilhar da ideia de Freire ${ }^{8}$ ao destacar que o olhar dos sujeitos sobre a própria realidade pode estar influenciado pelo o que se denomina "consciência ingênua". A interpretação da licencianda pode ter sido influenciada pelo fato de a etapa diálogos descodificadores, constituinte da investigação temática, não ter sido promovida, indicando um possível limite na opção metodológica adotada - ainda que fundamentada em Sousa et $a l .^{23}$ - pelo formador na definição do tema. Nessa etapa se estabelecem diálogos problematizadores com cidadãos da localidade, entre os quais, os próprios estudantes, em que se pode apreender visões do contexto em que estão submetidos e de forma admissível, integrantes de uma "consciência ingênua". É importante registrar, contudo, que no processo de investigação do tema, diferentes instrumentos foram utilizados para obtenção de informações sobre a realidade dos estudantes, cuja análise posteriormente culminou na definição do tema.

A "consciência ingênua" também pode permear as compreensões de professores como discutido por Silva et al. ${ }^{41}$ e influenciar o processo de apreensão da realidade discente. Nessa direção, uma das licenciandas reconhece tacitamente que os conhecimentos docentes podem ter implicação na escolha de situações significativa do tema e, por sua vez, isso pode ter se caracterizado, em alguma medida, uma limitação mais implícita:

A partir do que foi coletado, também exigiu maiores esforços dos pesquisadores com relação à escolha de uma situação mais significativa. Sendo assim, com estudos e orientações, constatou-se que o esgoto poderia merecer maior atenção diante dos resultados obtidos. O que não significa que outras situações não merecem destaque. Visto isso, percebem-se várias situações que tem potencial para serem exploradas diante de suas respectivas relevâncias. Apesar disso, elas podem estar diretamente relacionadas ou submissas do tema escolhido: Moradia. (B) [grifo dos autores]

A licencianda destaca dificuldades na identificação de uma situação significativa e na definição do tema. Em suas próprias palavras, "A partir do que foi coletado, também exigiu maiores esforços dos pesquisadores com relação à escolha de uma situação mais significativa" [grifo dos autores]. De acordo com a descrição, podem ser realçados elementos que coadunam com dificuldades docentes sobre a incorporação da abordagem temática pautada em Freire,${ }^{8}$ atreladas às lentes teóricas utilizadas na interpretação da realidade. Nessa direção, Freire ${ }^{8}$ descreve a necessidade de reflexão crítica em torno das relações que o ser humano estabelece com o mundo.

A licencianda A também reforça o desafio ou dificuldade de identificação do tema:

[...] outro desafio foi encontrar um tema único para ser abordado no projeto, pois a realidade encontrada no bairro indicava outros temas que poderiam ser trabalhados, sendo que estes temas nunca estavam sozinhos, sempre em uma perspectiva social, governamental, econômica e educacional. (A)

Segundo a licencianda, os temas potenciais identificados para o estágio não se restringiam a uma área do conhecimento. Essa complexidade que envolve dada realidade implicou em um desafio às estagiárias, qual seja, identificar um tema. $\mathrm{O}$ exposto até momento dá indicativo que as licenciandas não manifestaram limitações referentes ao tempo disponível para o planejamento, ao contrário do que expõem Sousa et al. ${ }^{22} \mathrm{em}$ seu trabalho com professoras das escolas ao promoverem um processo formativo relativo à abordagem de temas, segundo fundamentação em Freire. ${ }^{8}$ Em nossa pesquisa as limitações parecem estar mais relacionadas com o próprio conhecimento que as licenciandas se apropriaram, ou já traziam consigo, sobre a abordagem de tema para poder selecioná-lo. Essas limitações emergem mesmo quando as licenciandas não tratam propriamente de limitações e potencialidades no processo de planejamento e desenvolvimento da abordagem do tema no estágio:

[...] processo requer dedicação e muito estudo, para conseguir englobar a contextualização do problema local, utilizando conteúdos de áreas diferentes para explicar e instigar o senso crítico dos alunos, formando assim cidadãos conscientes e críticos. (A)

A licencianda sinaliza apropriações do processo de redução temática estudado, como etapa do processo de investigação temática proposta por Freire. ${ }^{8}$ No entanto, parece ter se constituído em um limite a compreensão de que no estágio seria necessário abordar conhecimentos de outras áreas/componentes curriculares. De acordo com as referências estudadas pelas licenciandas não era função do professor de Química ensinar conteúdos de outras áreas do conhecimento/ componentes curriculares, uma vez que, sem negar a necessidade de totalidade, se respeitava a fragmentação que implica na valorização de cada área do conhecimento que compõe o currículo escolar. ${ }^{42}$

Outra limitação identificada nesse sentido, diz respeito à redução da abordagem temática à contextualização dos conteúdos de Química:

Neste modelo, podemos utilizar temas os quais vão problematizar e contextualizar os conteúdos de química (e de outras disciplinas), que necessitam ser inseridos no projeto para melhor entender e desenvolver o mesmo. (A)

De acordo com o que foi destacado pela licencianda, pode-se interpretar que o papel do tema se reduz a contextualizar os conteúdos. A licencianda expõe, de forma tácita, como uma potencialidade do desenvolvimento do estágio por meio de um tema a possibilidade de "problematizar e contextualizar os conteúdos de química". Contrariamente, os conteúdos estão subordinados ao tema, uma vez que são escolhidos para favorecer a compreensão do tema e das situações significativas. Em outras palavras, os conteúdos são escolhidos de acordo com o tema selecionado. Na perspectiva de abordagem temática adotada é possível justificar porque determinados conteúdos são priorizados em detrimento de outros, como assinalam Delizoicov, Angotti e Pernambuco ${ }^{14}$ ao defenderem as etapas da investigação temática como estruturantes do currículo escolar. Contudo, entende-se que a licencianda pode estar explicitando um conhecimento que combina conhecimentos estudados sobre abordagem temática com outros de contextualização no ensino de química em que, inversamente, os temas estão subordinados aos conteúdos previamente selecionados. É preciso reconhecer também que o contexto de estágio supervisionado em que a escola possui um plano de ensino previamente estabelecido para a componente curricular e que foi objeto de estudo das licenciandas, pode ter contribuído, em alguma medida, para essa compreensão.

De outra parte, o apontamento explícito de limitações por parte das licenciandas também dá indicativos de que se apropriaram dos conhecimentos abordados no processo formativo. Por exemplo, uma das licenciandas destaca o caráter fortemente disciplinar do projeto que desenvolveram:

Diante dos objetivos estabelecidos com o projeto reconhece-se que apenas os conhecimentos da área de Ciência/ Química são insuficientes para promover a melhor atuação 
dos estudantes como cidadãos, de acordo com a realidade em que estão inseridos. Portanto, um melhor desenvolvimento do projeto seria em diálogo com outras componentes curriculares. (B)

A articulação entre a componente curricular Química e outras na abordagem do tema se constituiu em um limite. Nas componentes curriculares que antecedem o estágio no referido curso de Licenciatura em Química não há uma articulação com componentes curriculares de outros cursos de licenciatura da instituição. Isso colabora para desfavorecer a etapa de redução temática com a participação de especialistas de diferentes áreas do conhecimento e, por conseguinte, corrobora a visão excessivamente disciplinar de desenvolvimento do estágio supervisionado.

A licencianda B reconheceu outra limitação que foi a supervalorização de conteúdos conceituais em detrimento de outros:

Apesar da nossa formação e das orientações durante a elaboração do projeto, ainda é muito comum em nossas práticas a supervalorização dos conteúdos conceituais em detrimentos de outros. (B)

Ainda que a elaboração do projeto estivesse sob influência das ideias de Freire, ${ }^{8}$ as licenciandas reconheceram uma demasiada valorização de conteúdos conceituais. O que é coerente com o estudo de Strieder, Watanabe-Caramello e Gehlen ${ }^{43}$ que descreve preocupações docentes em torno da abordagem conceitual. Pautadas nessa valorização as autoras salientam que é possível que o ensino contemple minimamente a humanização dos discentes. ${ }^{8}$ Portanto, destaca-se aqui um possível papel da problematização que permeou a formação das licenciandas, dado o reconhecimento da limitação descrita.

Em suma, entende-se que a definição de um tema e dos conteúdos subjacentes, na compreensão das licenciandas foi permeada por limitações durante seu processo formativo. A análise sugere que as licenciandas foram influenciadas por compreensões que valorizam os conteúdos conceituais como definidoras do conteúdo programático. Nisso ficou implícito também o potencial da escrita no diário virtual coletivo e da problematização para a reflexão sobre a permanência de certos conhecimentos no processo formativo. A influência do processo de problematização também foi identificada por Gonçalves, Biagini e Guaita ${ }^{10}$ como uma característica importante à apropriação do conhecimento.

\section{As atividades de organização do conhecimento nas aulas de Química}

Sobre as atividades de organização do conhecimento nas aulas de Química, as licenciandas destacaram limitações. Entre elas, a disponibilidade de materiais coerentes com a perspectiva teórico-metodológica adotada. Por exemplo:

Com relação aos problemas encontrados para desenvolver o projeto desde o início até o atual momento, acredito que seja em encontrar textos e atividades contextualizadas para serem trabalhadas com os alunos. (A)

Há necessidade de ter à disposição do professor materiais didáticos que estejam em diálogo com a perspectiva de educação defendida. Além dos textos propriamente utilizados, é importante considerar a natureza do processo de leitura, que em uma perspectiva progressista, de acordo com Guaita e Gonçalves, ${ }^{44}$ precisa também contemplar o diálogo que se inicia no estudo da realidade. ${ }^{8} \mathrm{Em}$ outras palavras, é um diálogo que envolve a leitura de mundo e leitura da palavra promovida pelos estudantes. ${ }^{45}$ Em sintonia com a necessidade de considerar a natureza da leitura valorizada no processo educativo, a outra licencianda expôs considerações sobre a potencialidade da atividade:

[...] alguns alunos conseguiram melhor explicar as questões propostas inicialmente após a leitura do texto. (B)

Ela apreendeu indicativos de apropriação dos conhecimentos estudados por meio de uma estratégia de leitura utilizada na organização do conhecimento sustentada em Guaita e Gonçalves. ${ }^{44}$ Para os autores, a apropriação de determinados conteúdos por meio da leitura não implica que as chamadas concepções ingênuas sejam abandonadas. Nesse sentido é importante destacar as limitações atreladas à leitura de textos realizada com os estudantes:

Para minha surpresa, surgiram poucas dúvidas, principalmente quanto aos parâmetros apresentados para o esgoto sanitário, de acordo com a resolução do Conama. Isso, porque após estudar um pouco mais, percebi possíveis correlações e justificativas de analisar alguns dos parâmetros. (B)

De acordo com a licenciada, o desenvolvimento da atividade de leitura deveria estar voltado à explicitação de questionamentos por parte dos estudantes a respeito dos aspectos abordados para o tratamento de esgoto. No entanto, a carência de indagações discentes foi uma característica igualmente identificada por Guaita e Gonçalves ${ }^{44}$ na utilização da mesma estratégia de leitura. Nesse caso, o limite pode estar na dificuldade de descontruir uma cultura de silêncio, mais presente do que o desejável na cultura escolar. Apesar de a estratégia de leitura não estar centrada unicamente na voz do professor, ficou latente a necessidade de empreender mais esforços para emergir a curiosidade epistemológica ${ }^{34}$ entre os estudantes.

Assim como se apontou na categoria anterior, nesta se podem caracterizar também as limitações nos conhecimentos das licenciandas sobre aquilo que caracterizaram como limitação no planejamento e desenvolvimento do estágio supervisionado. Segue um exemplo sobre a interpretação de uma das licenciandas sobre a necessidade de responder aos alunos:

Ensinar não é tarefa fácil, [...], pois ele [o professor] precisa estar preparado para responder questões que não estavam no roteiro, $[\ldots]$. (A)

Sobre o exposto pela licencianda, é possível destacar as considerações de Freire ${ }^{34}$ acerca da necessidade de o professor responder às indagações discentes. Para o autor, é imperativo o professor reconhecer junto aos estudantes que nem sempre se tem respostas às suas perguntas. Essa é uma postura que colabora, inclusive, para os estudantes se sentirem seguros com as respostas que o professor consegue expressar às suas perguntas.

No que concerne aos trabalhos em grupo a licencianda B identificou limites e potencialidades no seu desenvolvimento:

Entretanto, percebi que nem todos os grupos ou membros de um grupo mostraram interesse e realizaram a tarefa de acordo com a proposta inicial. Sendo assim, talvez para a próxima aula, possamos dividir a turma e se for o caso, pedir para que os grupos entreguem a atividade proposta. [...] Por outro lado, foi surpreendente que alguns grupos se organizaram de tal forma que todos os membros conseguiram avançar nas discussões se apropriando dos conhecimentos. (B) 
O trabalho em pequenos grupos é algo que precisa ser ensinado aos estudantes. ${ }^{46}$ Existem aprendizagens de caráter atitudinal que são necessárias na dinâmica mencionada, como o respeito às opiniões dos colegas, saber ouvir, saber renunciar a determinadas opiniões quando for o caso, solidariedade, etc. Essas aprendizagens são reconhecidamente morosas e precisam ser perseguidas para favorecer o trabalho em grupo.

Além disso, foram identificadas limitações vinculadas ao desenvolvimento de atividades experimentais:

A participação dos alunos foi intensa, requerendo um pouco de atenção dos mesmos, pois parecia que eles estavam um pouco dispersos na execução do experimento, talvez precisase trabalhar melhor o envolvimento do grupo para executar o experimento sem causar tumulto. (A)

A licencianda chama atenção para a dificuldade de promover o trabalho em pequenos grupos durante as atividades experimentais. Em que pesem essas dificuldades que merecem ser objeto de reflexão, é preciso considerar o que Reigosa Castro e Jímenez Aleixandre ${ }^{47}$ expõem sobre os trabalhos em pequenos grupos em atividades experimentais. Para os autores, essas atividades podem colaborar para endossar no entendimento de estudantes o caráter social das atividades científicas - considerando que se constitui como objetivo do ensino de Ciências da Natureza o ensino não somente dos conteúdos da Ciência, mas também de seus processos - bem como de que a aprendizagem possui uma dimensão social.

Apesar das limitações apontadas, houve reconhecimento de que os estudantes se apropriaram dos conhecimentos estudados, de modo a caracterizar uma potencialidade no desenvolvimento da abordagem temática:

[...] após uma releitura com o grupo percebeu-se que os alunos se apropriaram do conhecimento científico, pois demonstraram conhecimentos sobre a escala de $\mathrm{pH}$ e pontuaram que devido aos valores identificados tem-se consequências diretas na vida aquática e também para o ser humano, além de comentarem sobre a necessidade de realizar outras análises. (B)

De acordo com a licencianda foi possível ter indicativos de apropriação de conhecimentos ensinados aos estudantes da escola. A apropriação de conhecimentos (conceitos científicos, etc.) na perspectiva progressista de educação de Freire $^{31}$ é essencial para que os estudantes se constituam naquilo que esse autor denomina de ser mais. Para Freire, ${ }^{31} \mathrm{o}$ fato de o professor respeitar e promover a explicitação daqueles conhecimentos que os estudantes trazem consigo para o processo educativo não deve se confundir com uma defesa à "consciência ingênua". Ao contrário, a transformação de conhecimentos em decorrência do processo educativo, com a apropriação de conhecimentos sistematizados, é uma condição para o desenvolvimento de uma consciência crítica.

Ainda que em certos momentos as licenciandas tenham apontado limitações vinculadas à participação de estudantes da escola, ao final do estágio conseguem identificar de forma mais aguda como uma potencialidade do planejamento e desenvolvimento da abordagem temática no estágio, um movimento mais participativo por parte de discentes:

Diante das metodologias propostas, foi possível modificar a passividade em que os alunos podem ser submetidos no ensino tradicional, além de considerar as ideias prévias dos discentes, incentivar o trabalho em grupo e o respeito aos demais. (B)
É possível destacar a superação de perspectivas que se aproximam do que Freire ${ }^{8}$ denomina de educação bancária. As licenciandas valorizaram a explicitação das ideias discentes na construção de conhecimentos. Tal compreensão vai ao encontro do processo de humanização dos discentes. ${ }^{8}$ Segundo Freire ${ }^{34}$ a "leitura de mundo" deve preceder a "leitura da palavra". Cumpre registrar ainda que para Freire ${ }^{34}$ o diálogo entre docente e discente não exclui momentos explicativos. Em harmonia com isso está outro posicionamento da mesma licencianda:

Durante esse momento, que talvez merecesse certos ajustes, foi possível notar que algumas respostas dos discentes tinham muito potencial para serem problematizadas. (B)

Apesar de reconhecer a explicitação de conhecimentos discentes, a licencianda assume que em certas ocasiões esses não foram problematizados. Para esse fato podemos expor diferentes reflexões. Seja como for, é preciso considerar que o estágio em si se constitui em um tempo e espaço de aprendizagem para licenciandas - e para o formador igualmente. $O$ estágio não se reduz a um tempo e espaço de pura aplicação de conhecimentos estudados previamente. Por outro lado, essa possível limitação - não ter problematizado certos conhecimentos - guarda em si uma potencialidade, qual seja, a ideia de valorizar os conhecimentos discentes e o respeito a eles, em sintonia com a superação da "arrogância epistemológica", não raramente presente entre professores da área de Ciências da Natureza, como ressaltam Alves e Silva. ${ }^{20}$ Essa arrogância manifesta-se, por exemplo, na expressão de intolerância docente aos conhecimentos discentes.

Ainda sobre a explicitação dos conhecimentos discentes a licencianda B destaca:

[...] na problematização inicial [...] os mesmos [os alunos] mostraram-se bastante participativos e identificaram que além das localidades em que a escola está inserida, outros locais de alto poder aquisitivo apresentam problemas com o tratamento de esgoto. Sendo assim, se reconhece o quão significativo é esse conteúdo. (B)

Nesse caso, identificou-se a potencialidade da problematização inicial para a localização do problema abordado para além da localidade em que os estudantes estavam inseridos. Por outro lado, a ausência de comentários ou problematizações sobre o problema não se restringir à localidade pode guardar em si, um limite da abordagem temática no contexto do estágio. A ausência de problematizações e/ou reflexões sobre os limites dos conhecimentos explicitados, pode reforçar uma visão fatalista. Assim, ainda que os discentes identifiquem problemas, conivente com o processo desumanizante, o processo educativo não pode reforçar a opressão. Isso é caracterizado como um obstáculo à medida que não se valoriza as contradições sociais ali presentes. ${ }^{20}$

Por outro lado, as licenciandas explicitaram conhecimentos a respeito de atividades que buscavam favorecer a reflexão discente sobre a transformação da realidade, caracterizando potencialidades da abordagem temática:

Quanto ao recurso utilizado para a avaliação, que nesse caso foi a escrita da carta para o órgão responsável pelo saneamento básico da localidade [...], percebe-se que foi muito interessante, pois além de ser um recurso avaliativo, podemos incentivar a escrita e o trabalho em pequenos grupos. Além disso, com uma possível resposta dos responsáveis técnicos aos alunos, que elaboramos nesse momento, foi possível elogiar a apropriação do conhecimento dos discentes, bem como chamar a atenção de alguns pontos que não ficaram 
esclarecidos e refletir sobre procedimentos que necessitam ser adotados na determinação da qualidade dos cursos de água. (B)

A realização de atividades que buscassem proporcionar a reflexão dos estudantes sobre a realidade, considerando os conhecimentos sistematizados aprendidos, colabora para o processo de problematização dos conhecimentos explicitados e para direcionar o processo de apropriação de novos conhecimentos, que nesse contexto são relevantes. $\mathrm{O}$ exposto no fragmento também sugere a potencialidade da abordagem temática para tratar dos chamados conteúdos atitudinais. Por vezes, conteúdos que não estavam sequer explicitados no planejamento docente. Em relação à atividade em discussão, a licencianda acrescenta: "além de retomar pontos não totalmente esclarecidos é um recurso para continuação do conhecimento científico, necessário para melhor compreensão do problema significativo identificado inicialmente na localidade". Nesse caso, ressaltamos igualmente o potencial para a ressignificação dos conteúdos conceituais, cujo ensino se dá em articulação com conteúdos procedimentais e atitudinais - já destacados.

Em suma, identificaram-se conhecimentos das licenciandas sobre limites e potencialidades relativos às atividades de organização do conhecimento nas aulas de Química. Esses conhecimentos das licenciandas podem ser tomados, em alguma medida, como indicativos de suas apropriações a respeito da abordagem temática.

\section{CONSIDERAÇÕES FINAIS}

Da análise depreende-se que as licenciandas explicitaram conhecimentos relativos à abordagem temática planejada e desenvolvida no contexto do estágio supervisionado que remetem a limitações e potencialidades que possibilitam refletir sobre a proposta adotada pelo professor formador. A definição do tema e dos conteúdos, de acordo com as licenciandas, foi caracterizada por limitações. De outra parte, as atividades de organização dos conhecimentos nas aulas de Química foram caracterizadas não somente por limitações, como também por potencialidades. O conhecimento delas indicou limitações na seleção de textos didáticos, no desenvolvimento do trabalho em grupo e de atividades experimentais, por exemplo. Mas, ao mesmo tempo expressaram conhecimentos sobre potencialidades associadas à explicitação do conhecimento pelos alunos da escola e relativo à problematização desse conhecimento.

Do exposto, compreende-se que parte do conhecimento que as licenciandas expressaram como limitações do planejamento e desenvolvimento do estágio supervisionado foi também, em alguma medida, carregado por limitações atreladas aos conhecimentos que elas traziam consigo. Ou seja, às vezes as limitações estavam mais nos conhecimentos utilizados para interpretar determinadas situações como limite do que nestas situações em si.

Essas considerações reforçam a importância de promover ações para expor as reflexões sobre a própria prática. Assim, destaca-se que de certo modo, a perspectiva formativa planejada e desenvolvida no estágio supervisionado na formação inicial de professores de Química contribuiu à reflexão sobre a prática pedagógica. Nisso merecem relevo: i) o diário virtual coletivo que se constituiu como um contribuinte às reflexões a respeito das ações docentes empreendidas durante a componente curricular; e ii) a análise do diário virtual coletivo dentro da perspectiva do professor pesquisador sobre a própria prática. No reconhecimento da inconclusão é que a educação se torna um processo permanente. ${ }^{34}$ A pesquisa coletiva entre licenciandos em Química e professores formadores pode fomentar a perspectiva do professor pesquisador acerca da própria prática entre docentes da educação básica. De outra parte, favorece que o formador desenvolva uma reflexão sistematizada acerca da sua prática pedagógica, como ocorreu na pesquisa aqui disseminada. A partir da análise o formador pode revisar o processo educativo destinado a promover uma abordagem temática na formação inicial de professores de Química.

Nesse processo cabe destacar o papel da problematização pautada no trabalho de Gonçalves, Biagini e Guaita ${ }^{10}$ e Freire ${ }^{31}$ com constantes instantes de fomento à explicitação de conhecimentos e de apropriação de novos conhecimentos, mediados pela problematização. Por exemplo, a permanência de certos conhecimentos constituiu-se nesse processo de análise do diário virtual coletivo, mediado pela problematização, em um objeto de reflexão. Em outras palavras, pode-se realçar o papel que a pesquisa do professor sobre a própria prática pode assumir no processo de problematização. Nisso está subentendida uma compreensão da problematização em uma perspectiva mais contínua que não se limita a dado momento do processo formativo. Constitui-se como um desafio, portanto, incorporar a pesquisa do professor no contexto do próprio estágio supervisionado curricular, uma vez que neste trabalho a pesquisa foi fruto de uma organização após a finalização do estágio. Outro desafio é a sistematização de uma abordagem teórico-metodológica da pesquisa do professor da própria prática para que essa possa contribuir para a problematização no sentido exposto por Freire. ${ }^{31}$

Esses resultados podem sugerir uma resposta ao problema discutido na literatura, e abordado previamente, relativa ao estudo da abordagem temática na formação inicial de professores da área de Ciências da Natureza.

Portanto, a análise de conhecimentos de estudantes de licenciatura da área de Ciências da Natureza relativos à abordagem temática pode apontar indicativos para a melhoria dos processos formativos que buscam incentivar tal abordagem na educação básica. Ademais, é salutar a disseminação de propostas formativas desenvolvidas no contexto dos estágios supervisionados para que se possam vislumbrar a superação de "obstáculos" que se impõe à formação de professores em perspectivas inovadoras, de modo que se possa avançar no próprio campo da pesquisa sobre os estágios supervisionados nas licenciaturas, em especial naquelas da área de Ciências da Natureza.

\section{REFERÊNCIAS}

1. Stuckey, M.; Hofstein, A.; Mamlok-Naaman, R.; Eilks, I.; Studies in Science Education 2013, 49, 1.

2. Delizoicov, D.; Alexandria: Revista de Educação em Ciência e Tecnologia 2008, 1, 37.

3. Caamaño, A.; Educ. Quim. 2018, 29, 21.

4. Santos, W. L. P.; Sci. Educ. 2009, 93, 361

5. Halmenschlager, K. R.; Delizoicov, D.; Alexandria: Revista de Educação em Ciência e Tecnologia 2017, 10, 305.

6. Sousa, P. S.; Bastos, A. P. S.; Figueiredo, P. S.; Gehlen, S. T.; Alexandria: Revista de Educação em Ciência e Tecnologia 2014, 7, 155.

7. Halmenschlager, K. R.; Strieder, R. B.; Watanabe, G.; Silva, L. F.; Anais do X Encontro Nacional de Pesquisa em Educação em Ciências, Águas de Lindoia, Brasil, 2015.

8. Freire, P.; Pedagogia do Oprimido, $12^{\mathrm{a}}$ ed., Rio de Janeiro: Paz e Terra, 1983.

9. Neres, C. A.; Gehlen, S. T.; Anais do XI Encontro Nacional de Pesquisa em Educação em Ciências, Florianópolis, Brasil, 2017.

10. Gonçalves, F. P.; Biagini, B.; Guaita, R. I.; Investigações em Ensino de Ciências 2019, 24, 101 .

11. Delizoicov, D.; Tese de Doutorado, Universidade de São Paulo, Brasil, 1991.

12. Paiter, L. L.; Gonçalves, M. M.; Rodrigues, M.; Britto, N. S. Q.; Revista da SBEnBio 2016, 9, 5809

13. Delizoicov, D.; Revista de Ensino de Física 1983, 5, 85 
14. Delizoicov, D.; Angotti, J. A. P.; Pernambuco, M.; Ensino de Ciências: Fundamentos e Métodos, Cortez: São Paulo, 2002.

15. Demartini, G. R.; Anais do XI Encontro Nacional de Pesquisa em Educação em Ciências, Florianópolis, Brasil, 2017.

16. Giacomini, A.; Muenchen, C.; Educação On-Line 2017, 24, 51.

17. Solino, A. P.; Gehlen, S. T.; Investigação em Ensino de Ciências 2014, 19, 141.

18. Hunsche, S.; Silva, E. R. A.; Hirata, J. M.; Anais do XI Encontro Nacional de Pesquisa em Educação em Ciências, Florianópolis, Brasil, 2017.

19. Bomfim, M. G.; Gehlen, S. T.; Anais do XI Encontro Nacional de Pesquisa em Educação em Ciências, Florianópolis, Brasil, 2017.

20. Alves, A. H.; Silva, A. F. G.; Alexandria: Revista de Educação em Ciência e Tecnologia 2015, 8, 181.

21. Halmenschlager, K. R.; Stuani, G. M.; Souza, C. A.; Alexandria: Revista de Educação em Ciência e Tecnologia 2012, 4, 83.

22. de Sousa, P. S.; Bastos, A. P. S.; de Figueiredo, P. S.; Gehlen, S. T.; Alexandria: Revista de Educação em Ciência e Tecnologia 2016, 9, 3.

23. de Sousa, P. S.; Santos, L. H. S.; dos Reis, Y. A.; Gehlen, S. T.; Anais do XXI Simpósio Nacional de Ensino de Física, Uberlândia, Brasil, 2015.

24. Centa, F. G.; Muenchen, C.; Alexandria: Revista de Educação em Ciência e Tecnologia 2016, 9, 263.

25. Torres, J. R.; Gehlen, S. T.; Muenchen, C.; Gonçalves, F. P.; Lindemann, R. H.; Gonçalves, F. J. F.; Revista Brasileira de Pesquisa em Educação em Ciências 2008, 8, 1 .

26. Moraes, R.; Galiazzi, M. C.; Análise Textual Discursiva, Ed. Unijuí: Ijuí, 2007.

27. Pimenta, S. G.; Lima, M. S. L.; Estágio e Docência, Cortez: São Paulo, 2004.

28. Auler, D.; Muenchen, C.; Forgiarini, M. S.; Gehlen, S. T.; Griebeler, A.; Santini, E. L.; Strieder, R. B.; Scheneider, C. V.; Enseñanza de las Ciencias 2005, extra, 1 .

29. Delizoicov, D. Em Ensino de Física: Conteúdo, Metodologia e Epistemologia em uma Concepção Integradora; Pietrocola, M., org.; Ed. UFSC: Florianópolis, 2005, pp. 125-150.
30. Silveira, R. A.; Piaia, L.; Gonçalves, F. P.; Anais do XIX Encontro Nacional de Ensino de Química, Rio Branco, Brasil, 2018.

31. Freire, P.; Extensão ou Comunicação?, Paz e Terra: São Paulo,1977.

32. Zabalza, M. A.; Diários de Aula: Um Instrumento de Pesquisa e Desenvolvimento Profissional, Artmed: Porto Alegre, 2004.

33. Freire, P. Em Pesquisa Participante; Brandão, C. R., org.; $4^{\text {a }}$ ed., Editora Brasiliense: São Paulo: 1981, pp. 34-41.

34. Freire, P.; Pedagogia da Autonomia: Saberes Necessários à Prática Educativa, 30a ed., Paz e Terra: São Paulo, 1996.

35. Maldaner, O. A.; A Formação Inicial e Continuada de Professores de Química: Professores/Pesquisadores, Editora Unijuí: Ijuí, 2000.

36. Galiazzi, M. C.; Educar pela Pesquisa: Ambiente de Formação de Professores de Ciências, Editora Unijuí: Ijuí, 2003.

37. Rosa, M. I. P.; Investigação e Ensino: Articulações e Possibilidades na Formação de Professores de Ciências, Editora Unijuí: Ijuí, 2004.

38. Abell, S.; Research in Science Education 2005, 35, 281.

39. El-Hani, C. N.; Greca, I. M.; Ciência \& Educação 2011, 17, 579.

40. Almeida, M. C.; Barbosa, L. A. R. S.; El-Hani, C. N.; Sepulveda, C. Em Pesquisa Colaborativa e Inovações Educacionais em Ensino de Biologia; Sepulveda, C., Almeida, M. C., orgs.; UEPS Editora: Feira de Santana, 2016, pp. 17-47.

41. Silva, R. M.; Solino, A. P.; Sousa, P. S.; Fonseca, K. N.; Investigações em Ensino de Ciências 2016, 21, 127.

42. Delizoicov, D.; Zanetic, J. Em Ousadia no Diálogo: Interdisciplinaridade na Escola Pública; Pontuschka, N., org.; Loyola: São Paulo, 1993, pp. 9-15.

43. Strieder, R. B.; Watanabe-Caramello, G.; Gehlen, S. T.; Ensaio: Pesquisa em Educação em Ciências 2012, 14, 153.

44. Guaita, R. I.; Gonçalves, F. P.; Quim. Nova Esc. 2015, 37, 53.

45. Freire, P.; A Importância do Ato de Ler: Em Três Artigos que se Completam, 48 a ed., Cortez: São Paulo, 2006.

46. Bonals, J.; O Trabalho em Pequenos Grupos em Sala de Aula, Artmed: Porto Alegre, 2003.

47. Reigosa Castro, C. E.; Jiménez Aleixandre, M. P.; Enseñanza de las Ciencias 2000, 18, 275. 